\title{
Sacrospinous Fixation for Treatment and Prevention of Vault Prolapse: Study of 20 Cases
}

\author{
SK Kathpalia ${ }^{1 *}$, Col Ajai Srivastava ${ }^{2}$ and Maj Jayanta Biswas ${ }^{3}$ \\ ${ }^{1}$ Andaman Nicobar Islands Institute of Medical Sciences, India \\ ${ }^{2}$ Command Hospital, India \\ ${ }^{3} 164$ Military Hospital, India
}

Submission: March 05, 2018 ; Published: November 26, 2018

*Corresponding author: SK Kathpalia, Department of Obstetrics and Gynecology), Andaman Nicobar Islands Institute of Medical Sciences, Port Blair 744104 India

Abstract

Introduction: Some patients will develop prolapse of apex of vagina; called vault prolapse after hysterectomy especially these days when the longevity has increased. Fixation of vault of vagina to sacrospinous ligament called sacrospinous fixation is performed vaginally. In this study the operation was performed for both, as treatment of vault prolapse and for its prevention by performing it as an adjunctive procedure at the time of vaginal hysterectomy.

Material and Methods: The study was conducted at four different service hospitals for a period of three years. The purpose of this study was to evaluate the feasibility of this operation for treatment of vault prolapse and prevention of vault prolapse after vaginal hysterectomy. The follow up period was done for a minimum period of two years.

Results and Observations: 20 cases underwent sacrospinous fixation on the right side, procedure was performed in nine cases of vault prolapse and as an adjunctive procedure in eleven cases for prevention in cases undergoing vaginal hysterectomy. There was no case of injury to rectum or bladder.

Conclusion: Sacrospinous ligament fixation is a good and effective operation, it restores level I vaginal support and has many advantages as abdomen is not opened. This operation is not only very effective in cure of vault prolapse but may prevent its occurrence in future; hence authors would like to suggest performing this procedure electively at the time of vaginal hysterectomy.

Keywords: Vault; Prolapse; Vaginal hysterectomy; Repair

\section{Introduction}

Utero-Vaginal Prolapse (UVP) also known as Pelvic Organ Prolapse (POP) affects a large number of women. Many surgical procedures for its correction are performed annually in the United States [1,2]. More than ten percent of women will need surgery for POP or incontinence by the time they reach the age of eighty five. One third of them will require an additional repair procedure for prolapsed $[3,4]$. Some patients $[5,6]$ will develop prolapse of apex of vagina (called vault prolapse) after hysterectomy especially these days when the longevity has increased. Incidence of vaginal vault prolapse following hysterectomy has been quoted as approximately 0.5 percent [7]. Vault prolapse can occur after abdominal or vaginal hysterectomy, chances of its occurrence are there even after abdominal hysterectomy as the patients are usually not examined for pelvic floor weakness preoperatively and pelvic floor repair is not performed as a routine procedure. Women who have undergone hysterectomy and in whom the suspensory apparatus was not repaired are at increased risk for vault prolapsed [8-10].
Numerous operative techniques are described for the correction of vault prolapsed [11]. Abdominal and vaginal routes can be adopted for this; both have their own merits and demerits. Fixation of vault of vagina to sacrospinous ligament is the operation performed vaginally [12]. This operation popularly named 'Sacrospinous Fixation' or 'Sacrospinous Colpopexy' was introduced by Randall and Nichols [5]; the procedure can be done on one or both sides. Fixation of the vaginal apex to the sacrospinous ligament has many advantages. By using a transvaginal approach, the inescapable and potential problems of laparotomy are evaded and hospital stay as well as time to resumption of normal activities is shortened [13]. Sacrospinous fixation will cure the vault prolapse and at the same time if performed at the time of vaginal hysterectomy for advanced UVP; it should be able to prevent occurrence of vault prolapse in future. In our study the operation was performed for both, as treatment of vault prolapse and for its prevention by performing it as an adjunctive procedure at the time of surgery for advanced UVP 


\section{Material and Methods}

The study was conducted by the three contributory authors at four different service hospitals for a period of three years. The purpose of this study was to evaluate the feasibility of this operation for treatment of vault prolapse and prevention of vault prolapse after vaginal hysterectomy for advanced UVP. Total of twenty cases of sacrospinous fixation; all on right side were performed. The follow up period was done for a minimum period of two years. All cases were evaluated preoperatively for general fitness and staged in accordance with the International Continence Society Pelvic Organ Quantification (ICS POP-Q) staging system. An informed consent was obtained and all cases were operated in lithotomy position under spinal/epidural/ combined anesthesia.

\section{Procedure}

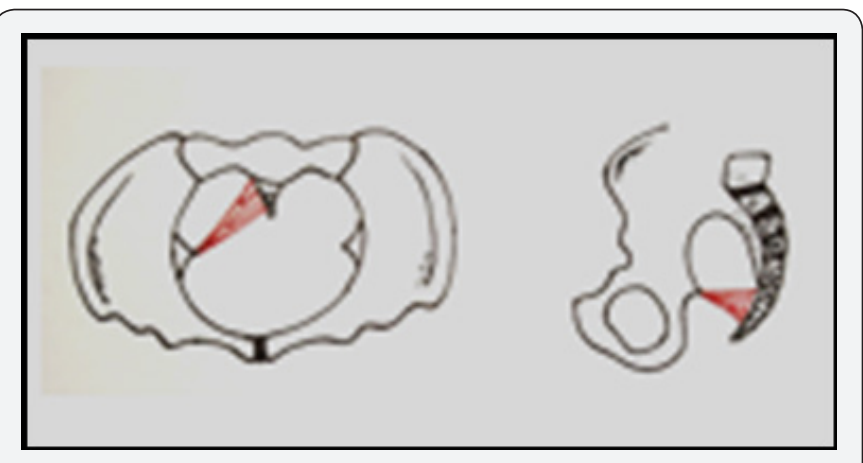

Figure 1: Applied anatomy of Sacrospinous ligament.

A vertical incision was given in the posterior vaginal wall beginning at the anterior edge of perineal body after liberal infiltration of saline with or without vasoconstrictor. The incision was extended upward till the apex of remaining posterior vaginal wall. Sharp and blunt finger dissection was carried out laterally keeping the rectal wall safe posteriorly. Dissection was carried out till the ischial spine on the right side. Pararectal fascia was penetrated and the para rectal space was dissected out till the spine along with sacrospinous ligament was easily felt or became visible. Sacrospinous ligament is a strong ligament which passes from ischial spine to lateral lower part of sacrum; forming the lower border of sacrosciatic notch (Figure 1). Once the ligament was delineated, number 1 polypropylene suture was passed through the middle of the ligament about one and half finger breadth away from the ischial spine to avoid injury to pudendal nerve and vessels. Passing of the suture was performed with the help of exposure and retraction by three retractors of different sizes. The confirmation of correct insertion was done by tugging on the thread.

This suture was passed through the apex of vagina on right side in such a way that the knot would get buried under vaginal wall after tying. Rest of the procedure was carried out and vagina closed in a T shaped manner. The knot was tied in the end deep into the vagina placing the tips of the fingers on the ischial spine so that vaginal wall came in direct contact with the ischial spine. The angle of vagina could be seen being retracted deep into the vagina on right side (Figure 2). The vagina was packed and an indwelling urinary catheter was introduced. Antibiotics were started preoperatively and continued for five days. Vaginal pack was removed after 24 hours and catheter after 48 hours. Intra and postoperative complications were recorded. If there was no complication the patient was discharged to home after five days and reviewed after two weeks. All the cases were kept for periodical follow up for a minimum period of two years. Demographic and medical data along with surgical complications and outcome were recorded and compared with data available in literature.

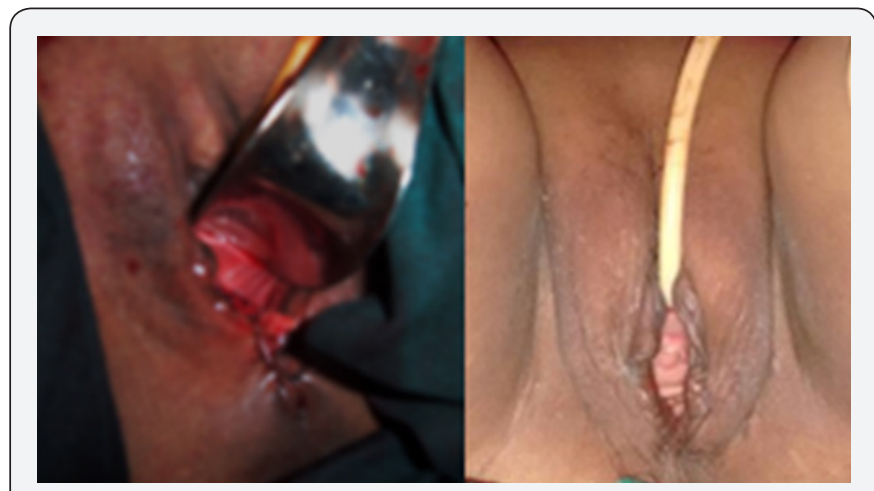

Figure 2: The right angle of apex of vagina getting retracted inside.

Results and Observations

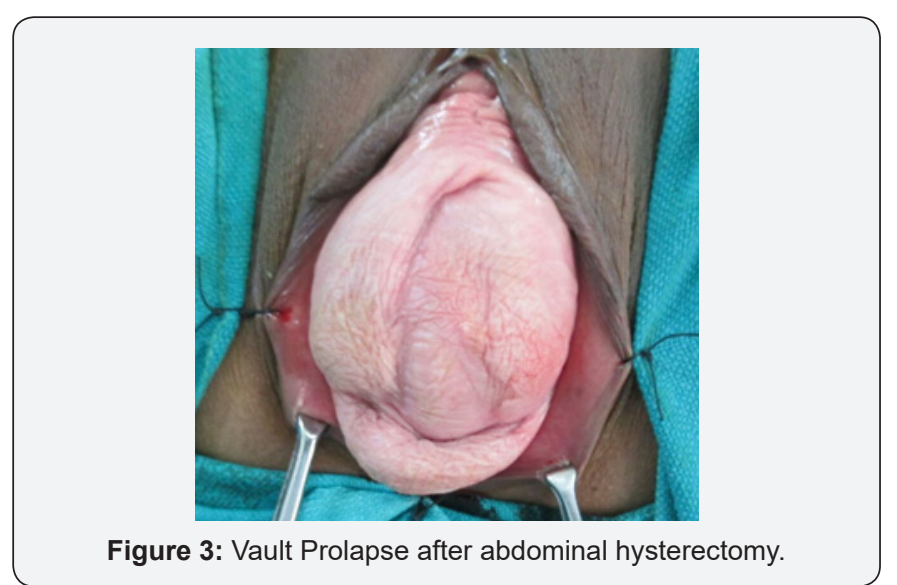

20 cases underwent sacrospinous fixation on the right side, procedure was performed in nine cases of vault prolapse (Figure 3 ) and as an adjunctive procedure in eleven cases for prevention in advanced cases of UVP undergoing vaginal hysterectomy with pelvic floor repair. Of the nine cases of vault prolapse, six had undergone vaginal hysterectomy and three abdominal hysterectomy. The mean age of the patients was $56.9 \pm 8$ years, average duration of time elapsed since hysterectomy was $7 \mathrm{yrs}$, the longest being 18 years (Figure 4) and shortest 3 years.

Of the eleven cases of vaginal hysterectomy one case had undergone Manchester-Fothergill operation six years back and one a cystocele repair eight years back. All the cases were multiparous and more than 50\% (12/20) had undergone sterilization. Co-morbidities are mentioned in 
Table 1. All the cases were operated under spinal/epidural or combined anesthesia. The standard procedure as described under 'Materials and Methods' was carried out. Sacrospinous fixation was performed after the other operations like vaginal hysterectomy, anterior repair and pelvic floor repair etc. had been carried out. One case complained of SUI (Stress Urinary Incontinence); TOT (Trans Obturator Tape) application was done before closure of anterior vaginal wall but the ends of the tape were not cut till the completion of the case. Average time taken to perform the operation for vault prolapse was $65 \pm 10$, and $22 \pm 4$ min extra were taken when it was done in addition to vaginal hysterectomy.

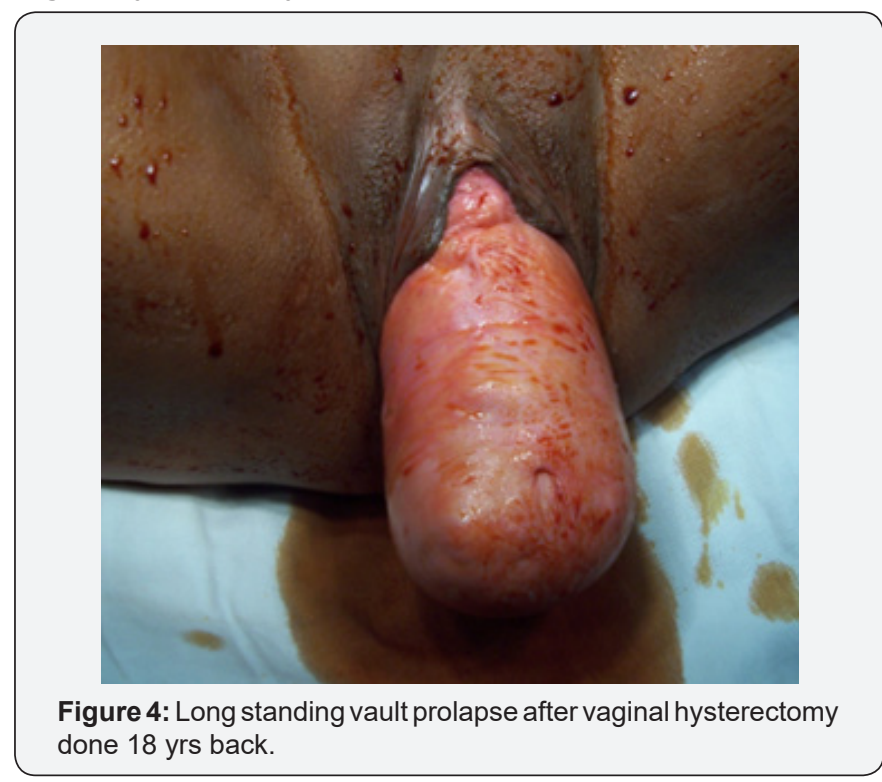

Table 1: Co-morbidities (some had more than one)

\begin{tabular}{|c|c|c|}
\hline S No & Co-morbidity & n (\%) \\
\hline 1 & Hypertension & $7(35)$ \\
\hline 2 & Diabetes & $3(15)$ \\
\hline 3 & Overweight* $^{*}$ & $12(69)$ \\
\hline 4 & ECG Changes & $4(20)$ \\
\hline
\end{tabular}

* Where BMI was more than $25 \%$

There was no case of injury to rectum or bladder, none of the cases required blood transfusion. One case developed bluish discoloration (Figure 5) of gluteal region along with fever 48 hours after surgery. The two possibilities entertained were; vascular injury resulting in blood trickling down or gluteal myositis. She responded well to empirical antibiotics, conservative and supportive measures (Figure 6). Per speculum examination of all the cases was performed after six weeks, the non-absorbable suture was not visible as it had got covered by epithelisation except in one case where it was visible. Since the patient did not have any complaint; the suture was left undisturbed. 18 cases were under follow up for more than two years; all were satisfied with the outcome of surgery and did not mention any fresh complaint but two were lost to follow up. Average duration of follow up was $30.5 \pm 3.1$ months. There was no major or minor complication during the follow up; one case had clinical symptoms of lower urinary tract infection who responded to antibiotics administered empirically though cultures were negative. There was one incidence of accidental needle prick injury to the assistant.

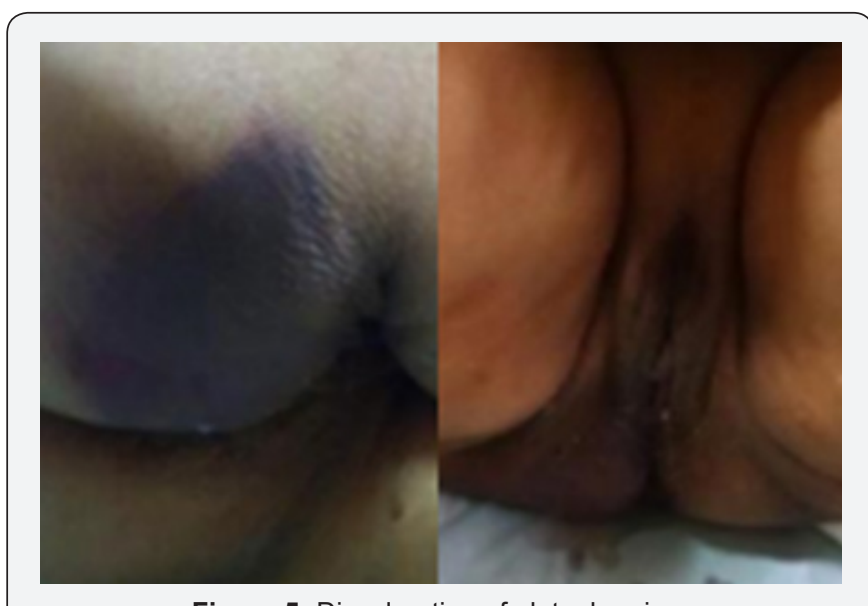

Figure 5: Discoloration of gluteal region.

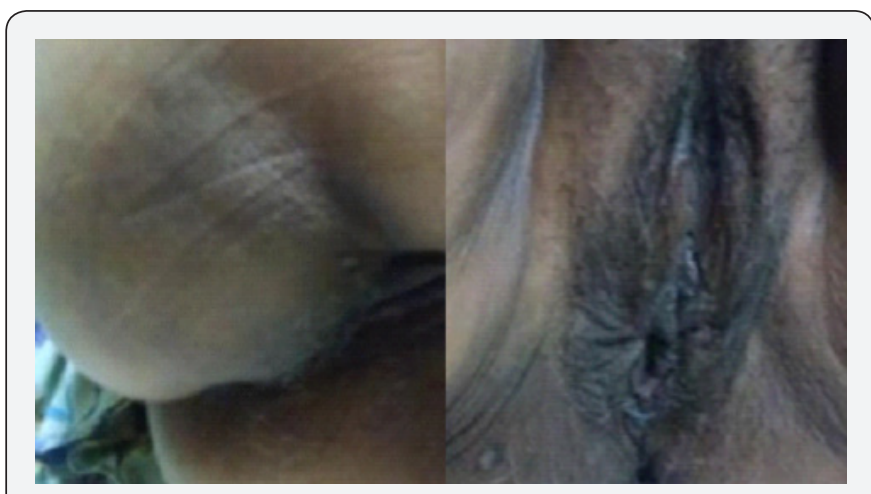

Figure 6: Response after ten days.

\section{Discussion}

The true occurrence of vaginal vault prolapse is unidentified 14 as many cases are lost to follow up after surgery but it has been observed that number of surgeries being performed for vault prolapse is increasing there by indicating that there is a strong need to learn the surgical techniques for correction of vault prolapse and also perform some extra procedure at the time of vaginal hysterectomy; which should be able to prevent vault prolapse in future [10]. There are many operations [11] which can be performed for correction and prevention of vault prolapse. There is no clear cut agreement on which operation is the best as most of the series of cases is small and all appear equally effective [15]. Two procedures 6 are more frequently carried out than the others; are abdominal sacrocolpopexy and transvaginal sacrospinous ligament fixation. The procedure of sacrospinous fixation has been put into practice for almost fifty years [16]. Sacrospinous ligament fixation is a good and effective $[17,18]$ operation, it restores level I vaginal support and has many advantages because abdomen is not opened as laparotomy has its own complications $[13,19]$. Some complications [20] of the procedure have been reported in literature which can be 
reduced by taking extra precautions. The overall complication rate for sacrospinous ligament fixation is $6.8 \%$ to $29 \%[21,22]$ We encountered one case of gluteal region discoloration which was suspected to be due to gluteal myositis [23] or vascular injury that responded well to empirical treatment and did not require removal of the suture.

All those who perform this procedure should be familiar with the anatomy (Figure 1) of this area to prevent complications to adjacent structures like rectum, vessels and nerves. One requires adequate exposure and good assistance to place the suture correctly without causing any accidental needle prick injury to the operating team as it happened in one case in this series.

Detailed preoperative assessment of urinary and rectal complaints is important to decide whether to combine any additional surgery along with this procedure. Urodynamic studies are ideal form of preoperative evaluation but may not be available in most of the institutions hence detailed history and clinical examination cannot be dispensed with. This operation is not only very effective in cure of vault prolapse but may prevent its occurrence also especially in women who are more at risk of its occurrence [24,25]; hence authors would like to suggest to perform this procedure electively at the time of surgery for advanced UVP. The chances of repeat surgery within 10 years of surgery is 7.4 percent when vaginal hysterectomy is done alone for prolapse and just 2 percent when simultaneous pelvic floor repairs are carried out at the time of hysterectomy [8].

A special hook (called Miya hook) was designed by Miyazaki in 1987 to pass the ligature through the sacrospinous ligament but the instrument is not easily available in our country. We were able to perform the operation with ordinary long needle holder. The procedure can be carried out in any hospital with patience and good assistance. This is not a difficult operation; has early postoperative recovery as laparotomy is avoided. Other procedures like "Prolift System" is effective, but expensive and still remains controversial $[26,27]$. The aim of the study was to find out the feasibility of performing this operation along with vaginal hysterectomy to prevent occurrence of vault prolapse in future and it is reiterated that the operation is feasible and it is advisable to carry out in all cases of advanced UVP

Limitations of the study the number of cases was small as it is not a common operation hence statistical analysis of the study could not be performed.

\section{References}

1. Jones KA, Shepherd JP, Oliphant SS, Wang L, Bunker CH, et al. (2010) Trends in inpatient prolapse procedures in the United States, 19792006. Am J Obstet Gynecol 202(5): 501e1-501e7.

2. Boyles SH, Weber AM, Meyn L (2003) Procedures for pelvic organ prolapse in the United States, 1979-1997. Am J Obstet Gynecol 188(1): 108-115.

3. Olsen AL, Smith VJ, Bergstrom JO, et al. Epidemiology of surgically managed pelvic organ prolapse and urinary incontinence. Obstet Gynecol 89(4): 501-506.
4. Asante A, Whiteman MK, Kulkarni A, Cox S, Marchbanks PA, et al. (2010) Elective oophorectomy in the United States: trends and inhospital complications, 1998-2006. Obstet Gynecol 116: 1088-1095.

5. Randall CL, Nichols DH (1971) Surgical treatment of vaginal inversion. Obstet Gynecol 38(3): 327-332.

6. Beer M, Kuhn A (2005) Surgical techniques for vault prolapse: a review of the literature. Eur J Obstet Gynecol Reprod Biol 119(2): 144-155.

7. DeLancey OL (1994) Vaginographic examination of the pelvic floor. Int Urogynec J 5(1): 19-24.

8. Eilber KS, Alperin M, Khan A, Wu N, Pashos CL, et al. (2013) Outcomes of vaginal prolapse surgery among female Medicare beneficiaries: the role of apical support. Obstet Gynecol 122(5): 1-5.

9. Blandon RE, Bharucha AE, Melton LJ (2007) Incidence of pelvic floor repair after hysterectomy: A population-based cohort study. Am J Obstet Gynecol 197(6): 664.e1-664.e7.

10. Gupta P (2015) Transvaginal Sacrospinous Ligament Fixation for Pelvic Organ Prolapse Stage III and Stage IV Uterovaginal and Vault Prolapse. Iran J Med Sci 40(1): 58-62.

11. Morley GW, DeLancey JO (1988) Sacrospinous ligament fixation for eversion of the vagina. Am J Obstet Gynecol 158(4): 872-881.

12. Richter K, Albrich W (1981) Long-term results following fixation of the vagina on the sacrospinous ligament by the vaginal route. Am J Obstet Gynecol 141(7): 811-816.

13. Monk BJ, Ramp JL, Montz FJ, Lebherz TB (1991) Sacrospinous ligament fixation for vaginal vault prolapse: complications and results. J Gynec Surg 7(2): 87-92.

14. Diwadkar GB, Barber MD, Feiner B, Maher C, Jelovsek JE (2009) Complication and reoperation rates after apical vaginal prolapse surgical repair: a systematic review. Obstet Gynecol 113(2 Pt 1): 367373.

15. Hu CD, Chen YS, Yi XF, Ding JX, Feng WW, et al. (2011) Comparison outcomes of three surgical procedures in treatment of severe pelvic organ prolapse and analysis of risk factors for genital prolapse recurrence. Zhonghua Fu Chan Ke Za Zhi 46(2): 94-100.

16. Rane A, Frazer M, Jain A, Kannan K, Iyer J (2011) The sacrospinous ligament: Conveniently effective or effectively convenient? J Obstet Gynaecol 31(5): 366-370.

17. Pasley WW (1995) Sacrospinous suspension: a local practitioner's experience. Am J Obstet Gynecol 173: 440-445.

18. Toukhy T, Bhaumik J, Katsimanis E (2003) Sacrospinous cervicocolpopexy with uterine conservation for uterovaginal prolapse in elderly women: an evolving concept. Am J Obstet Gynecol 188(3): 645-650.

19. Whiteside JL, Weber AM, Meyn LA, Walters MD (2004) Risk factors for prolapse recurrence after vaginal repair. Am J Obstet Gynecol 191(5): 1533-1538.

20. Ozdemir I, Somunkiran A, Topuz S, Iyibozkurt C, Duras DG, et al. (2006) Perioperative complications in abdominal sacrocolpopexy and vaginal sacrospinous ligament fixation procedures. Int Urogynecol J Pelvic Floor Dysfunct 18(3): 257-261.

21. Montefiore E, Barranger E, Dubernard G, Nizard V, Antoine JM, et al. (2007) Functional results and quality-of-life after bilateral sacrospinous ligament fixation for genital prolapse. Eur J Obstet Gynecol Reprod Biol 32(2): 209-213.

22. de Tayrac R, Faillie JL, Gaillet S, Boileau L, Triopon G, et al. (2012) Analysis of the learning curve of bilateral anterior sacrospinous ligament suspension associated with anterior mesh repair. European Eur J Obstet Gynecol Reprod Biol 165(2): 361-365. 
23. Faber VJ, van der Vaart HC, Heggelman BG, Schraffordt Koops SE (2008) Serious complication 1 year after sacrospinous ligament fixation. In Urogynecol J Pelvic Floor Dysfunct 19(9): 1311-1313.

24. Kudish BI, Iglesia CB, Sokol RJ, Cochrane B, Richter HE, et al. (2009) Effect of weight change on natural history of pelvic organ prolapse. Obstet Gynecol 113(1): 81-88.

25. Dallenbach P, Kaelin-Gambirasio I, Dubuisson JB, Boulvain M (2007) Risk factors for pelvic organ prolapse repair after hysterectomy. Obstet Gynecol 110(3): 625-632.
26. Kozal S, Ripert T, Bayoud Y, Menard J, Nicolacopoulos I, et al. (2014) Morbidity and functional mid-term outcomes using Prolift pelvic floor repair systems. Can Urol Assoc J 8: 605-609.

27. Benbouzid S, Cornu JN, Benchikh A, Chanu T, Haab F, et al. (2012) Pelvic organ prolapse transvaginal repair by the Prolift system: evaluation of efficacy and complications after a 4.5 years follow up. Int J Uro 19(11): 1010-1016.
Your next submission with Juniper Publishers will reach you the below assets

- Quality Editorial service

- Swift Peer Review

- Reprints availability

- E-prints Service

- Manuscript Podcast for convenient understanding

- Global attainment for your research

- Manuscript accessibility in different formats ( Pdf, E-pub, Full Text, Audio)

- Unceasing customer service

Track the below URL for one-step submission https://juniperpublishers.com/online-submission.php 